\title{
Root causes and persistent challenges in accelerating the abandonment of FGM/C
}

Jacinta Muteshi-Strachan

Population Council

Follow this and additional works at: https://knowledgecommons.popcouncil.org/departments_sbsr-rh

Part of the Demography, Population, and Ecology Commons, Family, Life Course, and Society Commons, International Public Health Commons, Maternal and Child Health Commons, Sociology of Culture Commons, and the Women's Health Commons How does access to this work benefit you? Let us know!

\section{Recommended Citation}

Muteshi-Strachan, Jacinta. 2016. "Root causes and persistent challenges in accelerating the abandonment of FGM/C," presentation at workshop in preparation for the 71st Session of the UN General Assembly, 29 June. Nairobi: Population Council. 


\title{
Evidence to End FGM/C (
}

\section{Root causes and persistent challenges in accelerating the abandonment of FGM/C}

\author{
Jacinta Muteshi, \\ Population Council
}

Accelerating the abandonment of FGM: Root causes, persistent challenges and promising practices

Workshop in preparation for the $71^{\text {st }}$ session of the General Assembly

$2^{\text {th }}$ June 2016

UN-New York 


\section{Introduction}




\section{Introduction}

- This presentation is a response to the continuing need for information by the General Assembly in its resolution 67/146, concerning the root causes and factors contributing to the practice of female genital mutilation, its persistent challenges, and the need for evidence and data to accelerate abandonment of FGM/C. 


\section{Outline of Presentation}

1. Root causes of FGM/C

2. Persistent challenges

3. Generating the evidence to accelerate the abandonment of FGM/C

4. Conclusion: Key Take Away Messages 


\section{Introduction}

\section{"FGM/C is a sensitive practice that is embedded within complex sociocultural systems. Reasons vary across countries and cultures}




\section{Slide 1. Root causes of FGM/C}

- Tradition and Custom

- The preservation of the cultural identity of the group: A community may provide several reasons or even contradictory reasons for the continuation of the practice.

"Bohra, participants mentioned several different reasons FGC is practiced within the Dawoodi Bohra community, such as cleanliness/hygienic, religion, being ostracized sexual control, tradition, and holding onto cultural roots combined together the reasons help demonstrate that female genital cutting or khatna is performed because it is considered an important part of the culture." (Mariya Taher, MA Thesis 2010) 


\section{Slide 2. Root causes of FGM/C}

- Marker of Life's Transitions

- A coming of age ritual where the girl transitions and is now identified as a woman. Older women who have undergone the ritual act as gate keepers of the custom

The Maasai communities in Kenya and Tanzania believe FGM to be a rite of passage and they only consider women who have been circumcised as adults.

In some rural communities in Egypt, the ritual is linked to a daughter's maturity and acquisition of her feminine identity (Abdel Shahid and Campbell 2015) 


\section{Slide 3. Root causes of FGM/C}

\section{- Social Status}

- For societies where FGM/C is widely practiced, not participating in the practice results in stigmatization, being treated as non-adults or exclusion from the society because they are not part of the norm.

"I don't want her friends to laugh at her. The non-initiated is not respected and she is repelled from gatherings." (Woman in a village in Sierra Leone) Plan UK "Traditions and Rights: Female genital cutting in West Africa" 2005

- Intergenerational pressure where older women view elimination of the ritual as an attack on their identity and customs.

For example: in the Somali refugee community in Maricopa County, Arizona where the men acknowledged strong matriarchal support for FGM/C (Johnson - Agbakwu et al. 2014) 


\section{Slide 4. Root causes of FGM/C}

- Chastity and Marriageability

- FGM is often driven by beliefs that the girl needs to be pure before marriage or that it reduces their sexual desires or libido avoiding promiscuity before and during marriage.

In Somali societies, the primary aim for girls and women is marriage and a girl is supposed to be a virgin at the time of marriage with her state of infibulation being checked to ensure this. (Talle A, 2010) 


\section{Slide 5. Root causes of FGM/C}

- Cleanliness, Hygiene and Beauty

- FGM is associated with cultural ideals of femininity and modesty, which include the notion that girls are clean and beautiful after removal of body parts that are considered unclean, unfeminine or male. In Guinea Bissau and Sudan its believed that the clitoris will grow unless cut (Gruenbaum 2006 and Johnson 2007)

- Promotes fertility

- Prepare girls for future childbirth, myths that if baby's had touches the clitoris during childbirth (baby) will die 


\section{Slide 6. Root causes of FGM/C}

- Religious Identity

- Despite FGM/C predating Islam and Christianity, communities such as in Indonesia and the Bafata region in Guinea Bissau believed that $F G M / C$ is a religious requirement

- Re-emergence or Adoption of FGM

- $F G M / C$ is dynamic and subject to change, recent adoption of the practice is linked to copying the traditions of neighboring groups as in Southern Chad and Senegal (Leonard 2000 and Dellenborg, 2004) 


\section{Slide 1. Persistent Challenges}

- All countries are making progress to reduces the prevalence of FGM/C but the pace of decline has been uneven

- Lack of adaption to the local context, there is no universal approach to accelerating abandonment of $\mathrm{FGM} / \mathrm{C}$

- Repressive enforcement of anti FGM/C laws- some communities resort to hiding or carry out the ritual at much younger ages for girls to avoid detection for example Maasai tribe in Kenya. Behaviour change based on fear is not sustainable 


\section{Slide 2. Persistent Challenges}

- Tradition and local leaders, such as chiefs, religious, circumcisers, men and even some medical personnel can contribute to upholding the practice.

- Economic Gain

a. For e.g. remuneration for the circumciser

"Practicing excision is my profession. It is my only income and it allows me to earn my living. I'm respected by the whole community and people listen to my advice." (Practitioner in a village in Sierra Leone)

b. Cost of celebrations - for societies that can afford to plan elaborate ceremonies, it's a lucrative business 


\section{Slide 3. Persistent Challenges}

- Medicalization

Trained health professionals who conduct FGM/C are violating girls and women's human rights to life, physical integrity and health and the fundamental medical ethic to "Do No Harm".

- Indonesia - we find more than half of girls have undergone the procedure by a trained medical professional

- Re-infibulation being performed for e.g. among Somali women even those who have immigrated to Europe and North America despite being prohibited by law (Vangen et al 2004) 


\section{Slide 4. Persistent Challenges}

- Interventions

Despite the existence of laws and policies to safeguard against FGM in many countries, limited progress enforcing legislation and implementing policies for a variety of reasons;

- Legislation: Practice of FGM/C may go underground, those who abide simply do so in fear of legal consequences not because of attitudinal change; shifts in cutting

- Funding limitations

- High Research for provision of rigorous evidence to support interventions

- Design challenges in measuring effects, change or impact for scale up of interventions 


\section{Generating Evidence: The beginning}




\section{Slide 1. Generating Evidence}

$\checkmark$ Evidence on why the practice sustains, is changing or abandonment has not started

$\checkmark$ Further exploration of the root causes and factors contributing to the practice of FGM/C:

- Medicalisation of cutting and reinfibulation after childbirth;

- Reduction in the severity of type of cutting practised; and

- Cutting at a younger age/adult age* 


\section{Slide 2. Generating Evidence}

$\checkmark$ Interventions: what is working, where, and why?

- Document the design, implementation and evaluation of key FGM/C interventions *

- Evidence of wider impacts of FGM/C interventions on girls and women's lives and whether FGM/C interventions address gender inequality, discrimination and violence and other harmful practices such as early, forced and girl marriages 


\section{Slide 3. Generating Evidence}

\section{Measurement}

- improve data collection, analysis, and interpretation

- Improve the measurement of prevalence

- expand the use of the FGM/C 2010 module to encourage uniform data collection;

- Conduct analyses of FGM/C data among daughters ages 0-14 that take into account the fact that girls who are not currently cut, may still face a risk of being cut in the future;

- Define and measure the complex social norms and cultural value systems that shape meaning \& significance

- Systematically document experiences of designing, implementing and evaluating complex interventions 


\section{CONCLUSION}




\section{Conclusion: Key Messages}

$\checkmark$ Where is FGM/C Practiced?:FGM/C is practiced globally and there are serious gaps in our understanding of the practice

$\checkmark \quad$ Need to understand prevalence: what are sources of data:

$\checkmark$ Essential to understand how change happens: Knowing where we target interventions, informing how we improve how we target interventions

$\checkmark$ Structural effects and the opportunities they present for abandonment or continuation not fully known

- The Gender script : This is how one becomes a girl or becomes a women

- The Context around FGM/C is changing: Global consensus to end $\mathrm{FGM} / \mathrm{C}$ has consequences

- The Power of custom and tradition: How can support to end the practice be undertaken without causing further harm to those already harmed by FGM/C 


\section{Evidence to End FGM/C}

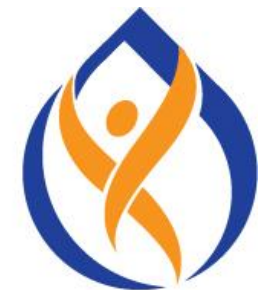

Research to Help Girls and Women Thrive

The Evidence to End FGM/C programme consortium generates evidence to inform and influence investments, policies, and programs for ending female genital mutilation/cutting in different contexts.

Evidence to End FGM/C is led by the Population Council in partnership with the Africa Coordination Centre for Abandonment of Female Genital Mutilation/Cutting (Kenya); Gender and Reproductive Health \& Rights Centre (Sudan); MannionDaniels, Ltd.; Population Reference Bureau; University of California, San Diego; and University of Washington. Evidence to End FGM/C is funded by UK aid by the UK Government.

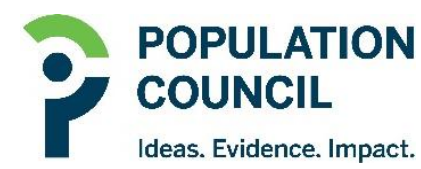

Ideas. Evidence. Impact.
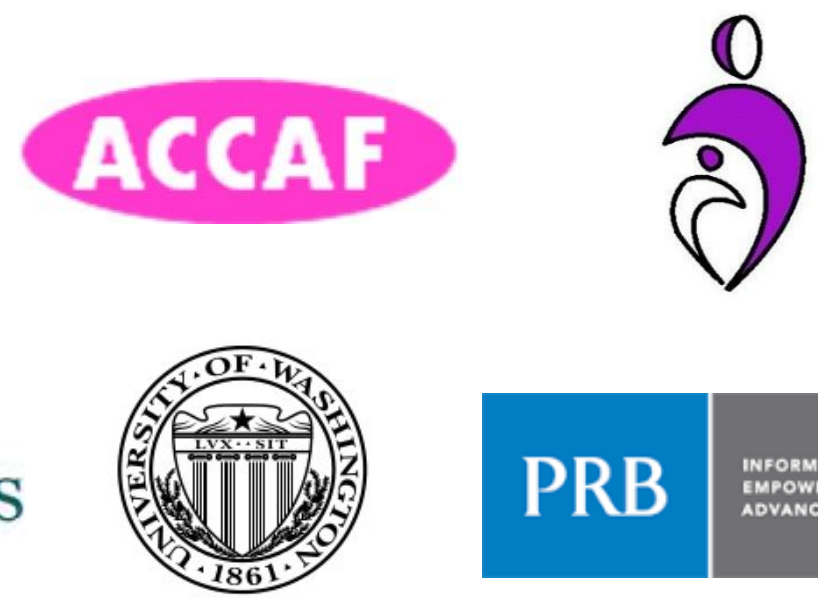
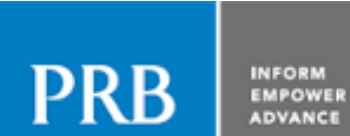


Leading Innovative Research 